\title{
Major Action of Endogenous Lysyl Oxidase in Clear Cell Renal Cell Carcinoma Progression and Collagen Stiffness Revealed by Primary Cell Cultures
}

\author{
Vitalba Di Stefano, ${ }^{*}$ Barbara Torsello, ${ }^{*}$ Cristina Bianchi, ${ }^{*}$ Ingrid Cifola ${ }^{\dagger}$ Eleonora Mangano, ${ }^{\dagger}$ Giorgio Bovo, \\ Valeria Cassina, ${ }^{*}$ Sofia De Marco, ${ }^{*}$ Roberta Corti, ${ }^{*}$ Chiara Meregalli, ${ }^{*}$ Silvia Bombelli, ${ }^{*}$ Paolo Viganò, ${ }^{\S}$ Cristina Battaglia, ${ }^{\dagger}$ \\ Guido Strada, ${ }^{\S}$ and Roberto A. Perego*
}

\begin{abstract}
From the School of Medicine and Surgery, * University of Milano-Bicocca, Monza; the Institute for Biomedical Technologies, ${ }^{\dagger}$ National Research Council, Segrate; the Anatomo-Pathology Unit, ${ }^{\ddagger}$ University of Milano-Bicocca, San Gerardo Hospital, Monza; the Urology Unit, ${ }^{\S}$ Bassini ICP Hospital, Milano; and the Department of Medical Biotechnology and Translational Medicine, "University of Milano, Segrate, Italy
\end{abstract}

\author{
Accepted for publication \\ May 23, 2016. \\ Address correspondence to \\ Roberto A. Perego, M.D., \\ School of Medicine and Sur- \\ gery, University of Milano- \\ Bicocca, Via Cadore 48, 20900 \\ Monza (MI), Italy. E-mail: \\ roberto.perego@unimib.it.
}

\begin{abstract}
Human clear cell renal cell carcinoma (ccRCC) is therapy resistant; therefore, it is worthwhile studying in depth the molecular aspects of its progression. In ccRCC the biallelic inactivation of the VHL gene leads to stabilization of hypoxia-inducible factors (HIFs). Among the targets of HIF-1 $\alpha$ transcriptional activity is the LOX gene, which codes for the inactive proenzyme (Pro-Lox) from which, after extracellular secretion and proteolysis, derives the active enzyme (Lox) and the propeptide (Lox-PP). By increasing stiffness of extracellular matrix by collagen crosslinking, Lox promotes tumor progression and metastasis. Lox and Lox-PP can reenter the cells where Lox promotes cell proliferation and invasion, whereas Lox-PP acts as tumor suppressor because of its Ras recision and apoptotic activity. Few data are available concerning LOX in ccRCC. Using an in vitro model of ccRCC primary cell cultures, we performed, for the first time in CCRCC, a detailed study of endogenous LOX and also investigated their transcriptomic profile. We found that endogenous LOX is overexpressed in CCRCC, is involved in a positive-regulative loop with HIF- $1 \alpha$, and has a major action on $\mathrm{ccRCC}$ progression through cellular adhesion, migration, and collagen matrix stiffness increment; however, the oncosuppressive action of Lox-PP was not found to prevail. These findings may suggest translational approaches for new therapeutic strategies in ccRCC. (Am J Pathol 2016, 186: 2473-2485; http://dx.doi.org/10.1016/ j.ajpath.2016.05.019)
\end{abstract}

Renal cell carcinoma (RCC) represents approximately 3\% of all human adult malignant neoplamsms ${ }^{1}$ and is resistant to radiation and chemotherapy. Nephrectomy may be curative but only in the early disease stages; however, approximately $40 \%$ of patients experience tumor progression and metastasis during follow-up. ${ }^{2}$ Clear cell RCC (ccRCC) represents approximately $75 \%$ of kidney carcinoma, ${ }^{1}$ and in approximately $90 \%$ of sporadic forms ccRCC is correlated with biallelic inactivation of the $V H L$ tumor suppressor gene, on chromosome $3 \mathrm{p}$, by somatic mutations or hypermethylation. ${ }^{3,4}$ VHL inactivation leads to stabilization of hypoxia-inducible factors (HIFs), HIF-1 $\alpha$ and HIF- $2 \alpha$, or only HIF- $2 \alpha$ in approximately $40 \%$ of cases because of deletion of HIF- $1 \alpha$ locus, on chromosome 14q. ${ }^{5}$ This stabilization determines a constitutive transcriptional activation of several target genes, ${ }^{6,7}$ many of which

Supported by grants PRIN 2004 (61903_004; R.A.P.), PRIN 2006 (69373_004; R.A.P.), Fondo d'Ateneo per la Ricerca Milano-Bicocca University (6152; R.A.P.), and Associazione Gianluca Strada Onlus (7920101001; R.A.P.), and grant FIRB 2007 (RBRN07BMCT). S.B. was a recipient of a postdoctoral fellowship and C.M. of a Ph.D. fellowship from Milano-Bicocca University. V.D.S. received a fellowship from Regione Lombardia-Fondazione Cariplo.

V.D.S. and B.T. contributed equally to this work.

Disclosures: None declared.

Current address of V.D.S., Frau Pharma srl, Agrate Brianza, Italy. 
are involved in ccRCC progression ${ }^{4,8}$ and also in its metabolic alterations. ${ }^{9}$ Among HIF- $1 \alpha$ target genes there is the lysyl oxidase (LOX) gene, on chromosome 5q23.2, that codes for a copper-dependent amine oxidase, ${ }^{10}$ which is an important player in tumor progression and metastasis formation. LOX, after intracellular posttranslational modifications, results in an inactive 50-kDa proenzyme of 417 amino acids (Pro-Lox). ${ }^{11}$ Once secreted in the extracellular matrix (ECM), Pro-Lox is proteolyzed by bone morphogenetic protein 1 and cleaved into the $32-\mathrm{kDa}$ active enzyme (Lox) and the $18-\mathrm{kDa}$ propeptide domain (Lox-PP). ${ }^{12}$ The extracellular active Lox enzyme catalyzes the covalent crosslinking of collagen and elastin in the ECM, increasing tensile strength and structural integrity of tissues, while producing hydrogen peroxide as a by-product. ${ }^{10}$ The Lox action can increase stiffness of cancer ECM and promote cellular adhesion and migration, favoring progression, invasion, and metastasis as shown using tumor cell lines of breast, brain, and colon. ${ }^{13-16}$ However, a tumor suppressor activity has also been ascribed to LOX, justifying its described upregulation or down-regulation even in the same cancer types, such as prostate and head and neck tumors. ${ }^{17}$

Although LOX was first described as an ECM protein, it also performs intracellular functions, and both active 32$\mathrm{kDa}$ enzyme and $18-\mathrm{kDa}$ propeptide can re-enter the cells by still unknown mechanisms. Active $32-\mathrm{kDa}$ Lox, through reactive oxygen species by-products and integrin stimulation, promotes cell proliferation and invasion of colorectal carcinoma cell lines by activating phosphatidylinositol 3kinase and the downstream FAK and Src signaling cascades. ${ }^{15,18}$ In fibroblasts, the nuclear localization of active Lox catalyzes the oxidation of $\mathrm{H} 1$ and $\mathrm{H} 2$ histone proteins, contributing to chromosome stability. ${ }^{19}$ Vice versa, the 18-kDa Lox-PP, acts as a tumor suppressor, having Ras recision activity ${ }^{20}$ and apoptotic activity by blocking the mitogen-activated protein kinases/extracellular signalrelated kinases pathways ${ }^{21}$ or impairing DNA repair pathways in the nucleus. ${ }^{22}$ It has also been reported that in colon carcinoma cell lines LOX and HIF- $1 \alpha$ potentiate each other to sustain tumor progression. ${ }^{23}$ All these findings suggest that LOX may have complex and different roles in tumorigenesis, depending on the transformation status of the cells, ${ }^{24}$ the molecular network, the cellular location, and the cell type in which it is active.

Regarding ccRCC, currently few data have been reported concerning mainly LOX expression in RCC tissues ${ }^{25-27}$ or cell lines. ${ }^{28} \mathrm{We}$ performed, for the first time in human ccRCC, a comprehensive and detailed study of endogenous LOX expression and functions. To overcome the difficulties and limitations attributable to tissue heterogeneity, we took advantage of a consolidated in vitro model of primary cell cultures that we obtain from normal kidney and ccRCC tissues. We previously extensively characterized these primary cell cultures for their proteomic, cellular, and genomic features, ${ }^{29-31}$ and we also investigated them for their transcriptomic profile. This in vitro model has been instrumental for the molecular and functional analysis of endogenous LOX related to ccRCC progression.

\section{Materials and Methods}

\section{Patients}

Twenty-four patients with ccRCC (14 men and 10 women; median age, 71 years; range, 46 to 86 years) treated by surgery were enrolled in this study after written informed consent. Histologic types, grade, and tumor stage were defined according to World Health Organization classification. ${ }^{32}$ Tumors were classified as $14 \mathrm{pT} 1,4 \mathrm{pT} 2,6 \mathrm{pT} 3$. Fuhrman grade were $2 \mathrm{G} 1,16 \mathrm{G} 2,5 \mathrm{G} 3,1$ not determined. The HIF-1 $\alpha$ protein was overexpressed in 18 patients and not detectable in six. All procedures were approved by the local ethic committee.

\section{Primary Cell Cultures and siRNA Transfection}

Primary cell cultures were obtained from specimens of tumor and matched renal cortex opposite to the tumor, collected after nephrectomy. The cellular composition was routinely evaluated by flow cytometry analysis as previously described. ${ }^{30}$ The renal cortex cultures were $>90 \%$ epithelial cells of proximal and distal tubule derivation, whereas the ccRCC cultures were $>90 \%$ epithelial neoplastic cells that originate from the transformation of proximal tubular cells. ${ }^{30,33}$ All the experiments were performed on cells at first or second passage. Subconfluent primary cell cultures were siRNA transfected with ON-TARGETplus SMART pool LOX siRNA (L-009810-00) or ON-TARGETplus Control Pool siRNA (D-001810-10-05) (Thermo Scientific Dharmacon, Lafayette, CO), using Interferin siRNA transfection reagent (Polyplus transfection; Thermo Scientific, Waltham, MA) according to the manufacturer's instructions. Transfected cells were analyzed after 48 hours.

\section{Transcriptomic Microarray Analysis and Bioinformatic Analysis}

Total RNA samples were extracted from primary cell cultures using the miRNeasy Mini kit (Qiagen, Hilden, Germany). RNA samples were quantified by ND-1000 spectrophotometer (NanoDrop Technologies, Wilmington, DE), checked for integrity on the 2100 Bioanalyzer instrument (Agilent Technologies, Palo Alto, CA), and stored at $-80^{\circ} \mathrm{C}$ until use. A total of 150 ng of RNA samples, from eight ccRCC and eight cortex primary cell cultures, were processed with the Ambion Whole Transcript Expression Kit (Applied Biosystems, Foster City, CA) and the GeneChip Whole Transcript Terminal Labeling kit (Affymetrix, Santa Clara, CA), according to the manufacturers' protocols. Biotinylated single-stranded DNA targets were fragmented and hybridized for 16 hours at $45^{\circ} \mathrm{C}$ onto GeneChip Human Exon 1.0 ST Arrays (Affymetrix). After washing and staining, 
fluorescent microarray images were acquired using the GeneChip Scanner 30007 G (Affymetrix) and analyzed with the GeneChip Operating software version 1.2 (Affymetrix). Raw intensity (.CEL) files are available at Array Express repository under accession number E-MTAB-4074 (Array Express, http://www.ebi.ac.uk/arrayexpress/experiments/EMTAB-4074, last accessed April 27, 2016). Probe signal intensities were quantified, normalized, and converted into gene expression values by the robust multiarray average procedure, and differentially expressed genes in ccRCC versus normal cortex cultures (DEG-PCs) were calculated by analysis of variance method using Partek Genomics Suite software version 3.5 (Partek Inc., St. Louis, MO). DEGs were selected based on a fold-change $\geq 2$ and a $P<0.05$, which was considered to indicate a statistically significant difference. Functional enrichment analysis on Gene Ontology (GO) biological processes terms was performed on our DEGPCs by ToppGene Suite (ToppGene Suite, https://toppgene. cchmc.org, last accessed April 27, 2016). A false discovery rate (Benjiamin-Hochberg correction) $<0.05$ was applied to define significantly enriched biological processes, limiting to GO terms with gene numbers between 200 and 1000 $(200 \leq \mathrm{n} \leq 1000)$. We compared our DEG-PC list to the list of differentially expressed genes related to ccRCC tissues (2493 DEG tissues, derived from RNA sequence analysis) reported as supplementary data by Wozniak et al. ${ }^{8}$ Comparison between $\mathrm{GO}$ biological processes enriched in ccRCC primary cultures and ccRCC tissues was performed using the ToppCluster tool, applying a false discovery rate threshold of 0.05 (ToppCluster, https://toppcluster.cchmc.org, last accessed April 27, 2016). ${ }^{34}$ Meta-analysis for $L O X$ gene expression was performed by using Oncomine Research Edition web tool (Oncomine, www.oncomine.org, last accessed October 13, 2015) comparing seven different ccRCC data sets (Oncomine identifications: Beroukhim, Gumz, Higginz, Jones, Lenburg, Vasselli, Yusenko).

\section{Real-Time PCR}

A total of $1 \mu \mathrm{g}$ of RNA was reverse transcribed with the high-capacity cDNA Reverse Transcription Kit (Applied Biosystems, Waltham, MA). TaqMan gene expression realtime PCR assays were performed in duplicate for each sample, following manufacturer's instructions using the indicated commercial kits (Lox: Hs00942480_m1; TGF-B3: Hs01086000_m1; Snail: Hs00195591_m1; Zeb-2: Hs00207691_m1; E-Cadherin: Hs01023894_m1; GAPDH: Hs99998805_m1; Applied Biosystem) and an ABI PRISM 7900HT Fast Real-Time PCR System (Applied Biosystems). The data were expressed as $2^{-\Delta \mathrm{CT}}$ or $2^{-\Delta \Delta \mathrm{CT}}$ when referred to a calibrator considered equal to 1 .

\section{Immunohistochemistry and Immunofluorescence}

Immunohistochemistry (IHC) was performed on matched ccRCC and cortex deparaffinated tissue sections of eight different patients' specimens. After retrieval and blocking, the sections were incubated overnight at $4^{\circ} \mathrm{C}$ with two different primary polyclonal rabbit antibodies against human LOX. The former, defined antibody A, is able to recognize the active Lox 32-kDa peptide and the Pro-Lox 50 $\mathrm{kDa}$ peptide (dilution, 1:200; 31238, Abcam, Cambridge, UK); the latter, here called antibody B, recognizes the LoxPP 18-kDa peptide and the Pro-Lox peptide (dilution, 1:200; NBPI-30012, Novus Biologicals, Littleton, CO). Renal sections were then incubated with secondary anti-rabbit antibody (dilution, 1:100; Dako, Glostrup, Denmark) coupled with horseradish peroxidase and then color was developed with 3-3'-diaminobenzidine. A semiquantitative evaluation of ccRCC tissue staining was performed, by two independent pathologists, in tissue slides at $\times 200$ magnification using ImageJ software version 1.50i (NIH, Bethesda, MD; http://imagej.nih.gov/ij) Cell Counter function and taking into account intensity and subcellular distribution of staining. About 1200 cells were analyzed in five different fields for each of the eight different tissue specimens.

Immunofluorescence was performed on primary cell cultures as we previously described ${ }^{35}$ using antibody A (dilution, 1:200), antibody B (dilution, 1:200), antibody against Paxillin (dilution, 1:50; clone 349, Becton Dickinson, San Jose, CA), and the Alexa Fluor 488 or 594 conjugated anti-rabbit or anti-mouse antibodies (dilution, 1:100; Invitrogen, Carlsberg, CA). Nuclei were counterstained with mounting DAPI (Invitrogen). Immunofluorescence images were obtained with confocal microscope Zeiss LSM710, using $63 \times$ objective, equipped with Zen software version 2009 (ZEISS Italia, Arese, Italy).

\section{Protein Extraction and Western Blot}

Primary cell cultures were lyzed in buffer containing 50 $\mathrm{mmol} / \mathrm{L}$ Tris $\mathrm{pH} \mathrm{7.4,} \mathrm{Nonidet} \mathrm{P} 40,0.25 \%$ deoxycholate, $150 \mathrm{mmol} / \mathrm{L} \mathrm{NaCl}, 1 \mathrm{mmol} / \mathrm{L}$ EDTA, protease inhibitor cocktail, and phosphatase inhibitor cocktail 1 and 2 (SigmaAldrich, Milan, Italy), and nuclear and nuclear-free fraction preparations were performed as previously described. ${ }^{35}$ Thirty micrograms of protein of cellular lysates was separated on NuPage $4 \%$ to $12 \%$ Bis-Tris precast gels (Invitrogen) and transferred to nitrocellulose membranes. To evaluate the secreted LOX proteins, primary cell cultures were grown until semiconfluence in defined media (Dulbecco's modified Eagle's medium F12, $5 \mu \mathrm{g} / \mathrm{mL}$ of insulin, $5 \mu \mathrm{g} / \mathrm{mL}$ of transferrin, $5 \mathrm{ng} / \mathrm{mL}$ of sodium selenite, 36 $\mathrm{ng} / \mathrm{mL}$ of hydrocortisone, $40 \mathrm{pg} / \mathrm{mL}$ of triiodothyronine, 20 $\mathrm{ng} / \mathrm{mL}$ of epidermal growth factor; all from Sigma-Aldrich) that were collected, centrifuged at $530 \times \mathrm{g}$, and left overnight at $-20^{\circ} \mathrm{C}$ with four volumes of ethanol $100 \%$. These media were then centrifuged twice at $13,000 \times g$ for 30 minutes at $4{ }^{\circ} \mathrm{C}$, and the whole protein pellets were suspended in loading buffer for gel separation and membrane transfer as for cell culture lysates. The membranes, after blocking, were probed overnight at $4^{\circ} \mathrm{C}$ with antibodies 
against LOX (antibody A, dilution, 1:500; antibody B, dilution, 1:500), $\beta$-actin (dilution, 1:1000; A2066, Sigma), HIF-1 $\alpha$ (dilution, 1:500; NB100-132, Novus Biological), $\mathrm{N}$-cadherin (dilution, 1:1000; 32/N, Becton Dickinson), E-cadherin (dilution, 1:1000; Becton Dickinson), paxillin (dilution, 1:1000; 2542, Cell Signaling, Boston, MA), phosho-Y118 paxillin (dilution, 1:1000; 2541, Cell Signaling), vimentin (dilution, 1:1000; V9, Dako), and $\alpha$-smooth muscle actin (dilution 1:1000; 14A, Dako). Secondary antibodies coupled with horseradish peroxidase and SuperSignal West Dura Detection System (Pierce, Rockford, IL) were used to detect protein bands. Densitometric values of specific bands were normalized with corresponding $\beta$-actin band intensities, unless otherwise specified. The protein bands of culture media were normalized by the number of cells collected from each plate.

\section{Fluorescence-Activated Cell Sorting Analysis}

ccRCC cells were stained with anti-cytokeratin fluorescein isothiocyanate antibody (dilution, 1:10; CK-6H5, Miltenyi Biotec, Bergisch Gladbach, Germany) 48 hours after LOX siRNA or control siRNA transfection. Fluorescence-activated cell sorting analysis was performed with MOFLOS ASTRIOS and data analyzed by Kaluza software version 1.2 (Beckman Coulter, Miami, FL). The acquisition process was stopped when 20,000 events were collected in the population gate.

\section{Functional Assays}

\section{Apoptosis}

Apoptosis was assessed using Caspase-Glo 3/7 Assay (Promega, Madison, WI), following manufacturer's instruction. A total of $2 \times 10^{4}$ cells of LOX silenced cultures have been seeded on 96-well plate in duplicate for each sample. Luminescence was recorded on spectrometer Victor Wolla C1420 (Perkin Elmer, Woltham, MA) at the wave length of 485 ex/527em $\mathrm{nm}$ and expressed as relative caspase $3 / 7$ activity with respect to the control considered equal to 1 .

\section{Cell Proliferation}

Cell proliferation of LOX silenced and control ccRCC primary cultures was determined in triplicate for each sample $\left(2 \times 10^{5}\right.$ cells) by MTT assay (Sigma-Aldrich). After medium withdrawal, $0.5 \mathrm{mg} / \mathrm{mL}$ of MTT solution was added to each well, and cells were incubated at $37^{\circ} \mathrm{C}$ for an hour and a half, then dimethyl sulfoxide was added and the final products quantified at $570 \mathrm{~nm}$. The optical density value of (LOX silenced sample/nonspecific siRNA sample) $\times 100$ indicated the percentage of proliferating cells with respect to the control.

\section{Migration Activity}

Migration activity was evaluated by Boyden chamber assay and wound healing assay as previously described. ${ }^{35}$ In the
Boyden chamber assay, $2 \times 10^{4}$ LOX silenced and control ccRCC primary cells were seeded in duplicate in the upper chamber of a Transwell device, equipped with $8-\mu \mathrm{m}$ microporous membranes (Corning Inc., New York, NY) and Dulbecco's modified Eagle's medium low glucose with 5\% fetal bovine serum. The lower compartments of Transwells were filled with Dulbecco's modified Eagle's medium low glucose $10 \%$ fetal bovine serum. The cells were incubated at $37^{\circ} \mathrm{C}$ in $5 \% \mathrm{CO}_{2}$ for 8 hours, and then Transwells were fixed in $100 \%$ methanol and stained with hematoxylin and eosin. Migration activity was assessed in each membrane at the bottom side by counting the number of cells in 10 randomized microscopic fields $(\times 100)$ and expressed as the percentage of migrated cells with respect to control. In the wound healing assay, the ccRCC cell monolayers were scratched with a pipette tip and photographed on an inverted microscope $(\times 100)$. Matched pair-marked wound regions were photographed again after 6 hours. Initial and final wound widths were measured and expressed as the percentage of wound recovery with respect to control. Two different operators (C.M. and S.D.M.), blinded to experimental treatment, evaluated both assays with ImageJ software version $1.50 \mathrm{i}$.

\section{Invasion Activity}

Invasion activity was evaluated in the same conditions of Boyden assay, but the upper side membrane was coated with $1 \mathrm{mg} / \mathrm{mL}$ of collagen (Invitrogen) to simulate the ECM. The data were expressed as the percentage of invading cells with respect to control.

\section{Adhesion Activity}

Adhesion activity of primary cell cultures was measured by the crystal violet assay. A total of $3 \times 10^{4}$ LOX silenced ccRCC cells and controls were seeded on wells, covered or uncovered with fibronectin $(10 \mathrm{mg} / \mathrm{mL}$ in water; SigmaAldrich), and incubated at $37^{\circ} \mathrm{C}$ in $5 \% \mathrm{CO}_{2}$ for 30 minutes. Cells were fixed in $4 \%$ formaldehyde (Sigma-Aldrich), washed, and stained with crystal violet $(0.05 \% \mathrm{w} / \mathrm{v}$ in $20 \%$ methanol) for 20 minutes. After washes, $1 \%$ sodium dodecyl sulfate solution was added, and the released violet dye from adhered cells was quantified at $550 \mathrm{~nm}$. The optical density value of (LOX silenced cells/control siRNA cells $) \times 100$ indicated the percentage of adhesion capability with respect to control.

\section{Collagen Matrix Stiffness Measurement by Atomic Force Microscopy}

Fifty microliters of $7.5 \%$ acrylamide and $0.4 \%$ bisacrylamide (Sigma-Aldrich) gel solution was delivered on round $25-\mathrm{mm}$ glass coverslips, and after polymerization, $300 \mu \mathrm{L}$ of Sulfo-SANPAH (Sigma-Aldrich) was added to gel surface. After 2 hours, $1 \mathrm{~mL}$ of $1 \mathrm{mg} / \mathrm{mL}$ of fresh collagen solution was added to the gel surface and incubated overnight at $37^{\circ} \mathrm{C} .{ }^{36}$ Phosphate-buffered saline-rinsed collagen-coated 
matrixes were then treated overnight at $37^{\circ} \mathrm{C}$ with i) control medium, ii) control medium of ccRCC primary cell culture plus $500 \mu \mathrm{M}$ BAPN LOX Inhibitor (Sigma-Aldrich), iii) conditioned medium of ccRCC primary cell culture, iv) conditioned medium of ccRCC primary cultures plus 500 $\mu \mathrm{M} \beta A P N, v)$ conditioned medium of ccRCC cells treated with control siRNA, and vi) conditioned medium of ccRCC cells treated with LOX siRNA. Stiffness measurements of differently treated collagen matrixes were performed in phosphate-buffered saline using standard atomic force microscopy (Nanowizard II, JPK, Berlin, Germany). The stiffness of matrixes was probed by the atomic force microscopy tip exerting a controlled force on the surface, and the elastic and plastic deformation of the sample was detected and recorded. The force-displacement curves between contact and 2000-nm deformation depth have been analyzed, and the softer the sample the larger the deformation recorded. To quantify the surface stiffness, we used the Young modulus, which is proportional to the ratio between the applied force and deformation. Young modulus was represented as fold-change with respect to control considered equal to $1 .^{36}$

\section{Statistical Analysis}

Data were analyzed using one-way analysis of variance and the $t$-test. $P<0.05$ was considered statistically significant. All data presented are expressed as means \pm SEM of at least three independent experiments, unless otherwise stated.

\section{Results}

\section{Transcriptomic Profiling of ccRCC and Normal Cortex Primary Cell Cultures}

To extend the molecular characterization of our primary cell culture in vitro model for its use in studying ccRCC, we performed the transcriptome profiling of eight ccRCC versus eight cortex primary cultures by using Affymetrix microarray technology. We globally found that the gene expression profiling well discriminated tumor from normal cortex primary cell cultures evidencing 1049 DEGs (552 up- and 497 down-regulated genes) in ccRCC compared with normal kidney cultures (Supplemental Table S1). Using the ToppGene suite, we found a significant functional enrichment for several biological processes that were related to ccRCC development, ${ }^{8}$ such as immune and inflammatory response, wound healing, vasculature development, metabolic process, hypoxia response, ECM organization, mitogenactivated protein kinases cascade, and cell proliferation. These were represented mostly among the first 50 enriched terms as reported in Table 1 (complete list in Supplemental Table S2).

To verify whether ccRCC primary cultures can be considered as a good in vitro model to represent and study
ccRCC tissue, we compared the transcriptomic profile of our tumor primary cell cultures (1049 DEG-PCs) to that of ccRCC tissues (2493 DEG tissues) ${ }^{8}$ obtained with the more sensitive approach of next-generation sequencing (RNA sequencing). We found that 552 of 1049 DEGs (52.6\%) of our cultures were shared (data not shown). In addition, by using the ToppCluster tool, we found that ccRCC primary cell cultures and tumor tissues shared many GO biological processes, indicating a good similarity between ccRCC cultures and tissues (Supplemental Table S3), and 118 of the shared GO terms had the highest significant scores $\left(P=10^{-9}\right)$. The GO terms, such as vasculature development, hypoxia response, cell adhesion and proliferation, ECM organization, cell migration, and wound healing, were represented among the highest enriched terms (Supplemental Table S3), suggesting that our cultures could be used as tools to study the aspects related to ccRCC progression. Among the genes involved in tumor progression, $L O X$ is recognized to have an important role. ${ }^{10}$ Interestingly, in several biological processes relevant for ccRCC progression (ECM organization, vasculature development, and wound healing) and enriched in both ccRCC primary cultures and tissues, we found the recurrence of LOX gene (Supplemental Table S4), which revealed a significant up-regulation in tumor versus normal cultures (fold change $\left.=7.7, P=10^{-5}\right)($ Supplemental Table S1). By using the Oncomine Research Edition database, we further confirmed the overexpression of LOX gene in seven different ccRCC data sets (tumor versus normal tissues), with fold-change values ranging from 4 to 34 $\left(P<10^{-4}\right)$ (Supplemental Table S5).

\section{Endogenous LOX Protein Expression in cCRCC and Normal Kidney Tissues}

To investigate the significance of LOX overexpression in ccRCC progression and invasion, we first evaluated the LOX protein expression in specimens of eight different cases of ccRCC and normal kidney tissues obtained from nephrectomies. IHC staining of LOX was performed with antibody A, which recognizes both active Lox $(32 \mathrm{kDa})$ and Pro-Lox (50 kDa), and with antibody B, which recognizes Lox-PP (18 kDa) and Pro-Lox (50 kDa) (Figure 1). The semiquantitative evaluation of nuclear and cytoplasmic positivity in ccRCC tissues was also reported in Table 2. Antibody A revealed in ccRCC tissues only few nuclei with a weak positive reaction (approximately $8 \%$ ) and the presence of only an intensified signal against the membrane borders in most cells $(82 \%)$, whereas in approximately $17 \%$ of cells a weak cytoplasmic signal was also present. In normal kidney tissue, the positive signal was heterogeneously represented. In cortex tissue, there was weak LOX staining in cytoplasm of proximal tubules, and most nuclei also had a faint positive signal. In medulla, there was a stronger staining in cytoplasm and 
Table 1 Top 50 Gene Ontology Biological Processes (GO BP) Enriched in 1049 DEGs

\section{GO BP}

Identification

G0:0002684

Name

Positive regulation of immune system process

G0:0050776 Regulation of immune response

G0:0001775 Cell activation

G0:0050778 Positive regulation of immune response

G0:0045321 Leukocyte activation

G0:0050900 Leukocyte migration

G0:0002253 Activation of immune response

G0:0009607

G0:0006954

$\mathrm{G0:0051707}$

G0:0043207

G0:0051094

G0:0001816

G0:0002252

G0:0045087

G0:0044283

G0:0051050

G0:1902533

G0:0042060

G0:0050878

G0:0072359

G0:0072358

$\mathrm{G0}: 0001568$

G0:0060326

G0:0001944

G0:0046649

G0:0070661

G0:0045937

G0:0010562

G0:0043410

G0:0036293

G0:0032101

G0:0030198

G0:0043062

G0:0001817

G0:0070482

G0:0045597

G0:0001666

$\mathrm{G0}: 0043408$
$P$ value

$2.50 \times 10^{-22}$

$3.05 \times 10^{-19}$

$8.22 \times 10^{-19}$

$2.39 \times 10^{-16}$

$4.01 \times 10^{-16}$

$3.99 \times 10^{-15}$

$4.06 \times 10^{-15}$

$4.05 \times 10^{-14}$

$5.02 \times 10^{-14}$

$1.23 \times 10^{-13}$

$1.23 \times 10^{-13}$

$1.42 \times 10^{-13}$

$1.78 \times 10^{-13}$

$6.57 \times 10^{-13}$

$6.71 \times 10^{-13}$

$1.46 \times 10^{-12}$

$2.13 \times 10^{-12}$

$2.43 \times 10^{-12}$

$2.73 \times 10^{-12}$

$2.96 \times 10^{-12}$

$3.03 \times 10^{-12}$

$3.03 \times 10^{-12}$

$3.52 \times 10^{-12}$

$4.57 \times 10^{-12}$

$1.51 \times 10^{-11}$

$2.43 \times 10^{-11}$

$2.55 \times 10^{-11}$

$3.43 \times 10^{-11}$

$3.43 \times 10^{-11}$

$3.98 \times 10^{-11}$

$6.23 \times 10^{-11}$

$7.89 \times 10^{-11}$

$8.05 \times 10^{-11}$ $8.90 \times 10^{-11}$

$9.47 \times 10^{-11}$

$1.01 \times 10^{-10}$

$1.26 \times 10^{-10}$

$1.33 \times 10^{-10}$

$1.61 \times 10^{-10}$

(table continues)
Table 1 (continued)

\begin{tabular}{|c|c|c|}
\hline $\begin{array}{l}\text { GO BP } \\
\text { Identification }\end{array}$ & Name & $P$ value \\
\hline G0:0002250 & Adaptive immune response & $1.89 \times 10^{-10}$ \\
\hline G0:0008284 & $\begin{array}{l}\text { Positive regulation of cell } \\
\text { proliferation }\end{array}$ & $1.99 \times 10^{-10}$ \\
\hline G0:0034097 & Response to cytokine & $2.11 \times 10^{-10}$ \\
\hline G0:0002521 & Leukocyte differentiation & $2.17 \times 10^{-10}$ \\
\hline G0:0048514 & Blood vessel morphogenesis & $2.61 \times 10^{-10}$ \\
\hline G0:0002764 & $\begin{array}{l}\text { Immune response-regulating } \\
\text { signaling pathway }\end{array}$ & $3.01 \times 10^{-10}$ \\
\hline G0:0006935 & Chemotaxis & $3.60 \times 10^{-10}$ \\
\hline G0:0042330 & Taxis & $3.87 \times 10^{-10}$ \\
\hline G0:0051240 & $\begin{array}{l}\text { Positive regulation of } \\
\text { multicellular organismal } \\
\text { process }\end{array}$ & $4.77 \times 10^{-10}$ \\
\hline G0:0000165 & MAPK cascade & $4.91 \times 10^{-10}$ \\
\hline G0:0042110 & T-cell activation & $5.69 \times 10^{-10}$ \\
\hline
\end{tabular}

A complete list of G0 BP terms is reported in Supplemental Table S2. MAPK, mitogen-activated protein kinases.

nuclei of collecting ducts. With antibody B, the signal was not homogeneously distributed in ccRCC tissues: nuclei revealed strong positivity in approximately $17 \%$ and weak positivity in $72 \%$ of the cells, whereas the signal was weak in most cytoplasms (89\%). In the cortex, weak staining was present in cytoplasm of proximal tubules, as with antibody A, and only a few nuclei had a faint positive signal. In some sections of cortex, it has been possible to observe the collecting ducts of medullary rays whose cells presented a stronger staining in cytoplasm and nuclei. In the medulla, there was weak staining in cytoplasm of collecting ducts but not a nuclear reaction. With both antibodies A and B, the glomeruli, distal tubules, endothelial cell of vessels, and thin and thick limbs of loops of Henle tested negative.

\section{Endogenous LOX Expression in cCRCC and Cortex Primary Cell Cultures}

To evaluate better LOX expression, we compared the cells of our ccRCC and cortex primary cultures that were cytologically more homogeneous. In 24 matched ccRCC and normal cortex primary cell cultures, we evidenced, by realtime PCR, that the LOX mRNA was significantly overexpressed in ccRCC cells, validating the transcriptomic data. The same samples, stratified in two groups according to HIF- $1 \alpha$ expression, revealed a significant LOX mRNA overexpression only in the group of 18 samples expressing HIF- $1 \alpha$ (Figure 2A), confirming that in ccRCC LOX gene is a direct target of HIF- $1 \alpha^{37}$

Five matched primary cell cultures of normal cortex and ccRCC expressing HIF- $1 \alpha$ were analyzed by Western blot (Figure 2B). The 50-kDa Pro-Lox proenzyme, studied with 


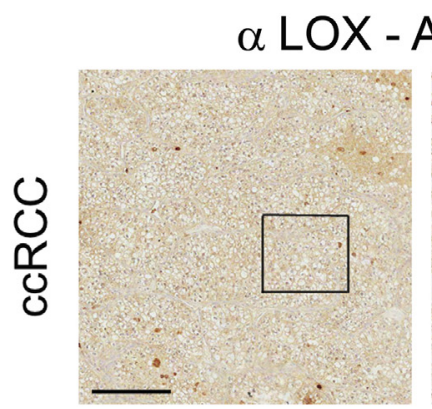

\section{Antibody A}
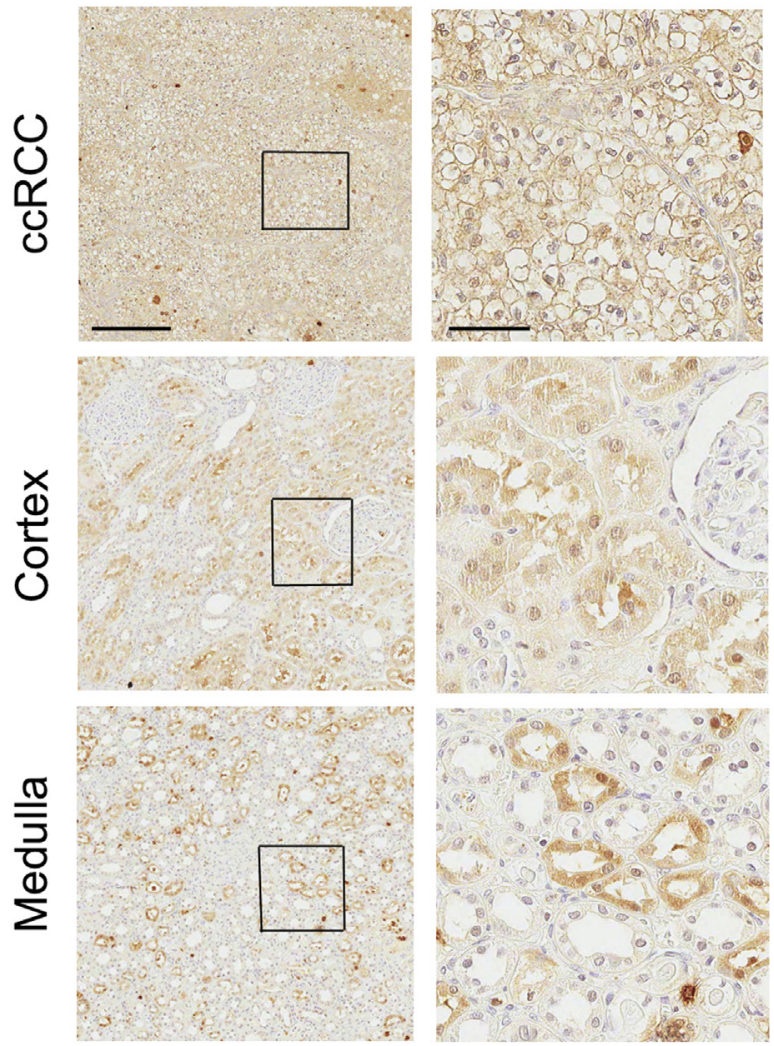

$\alpha$ LOX - Antibody B
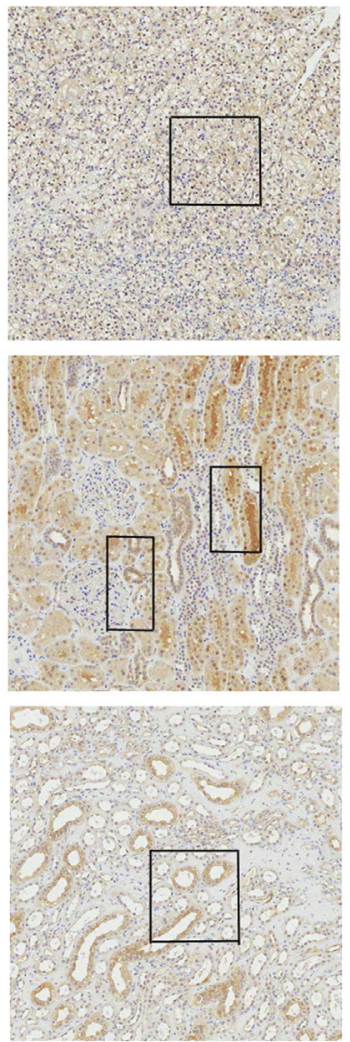
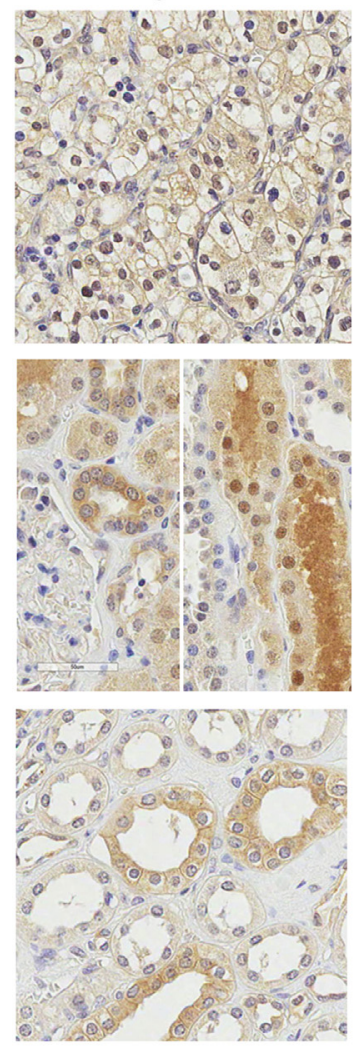

Figure 1 Representative images of LOX immunohistochemical analysis of hypoxia-inducible factor (HIF)-1 $\alpha$-expressing clear cell renal cell carcinoma (ccRCC) tissues and their matched normal kidney cortex and medulla tissues. Two different antibodies against LOX ( $\alpha$ LOX) have been used. Antibody A recognizes 50-kDa Pro-Lox and active 32-kDa Lox. Antibody B recognizes 50-kDa Pro-Lox and 18-kDa Lox-PP peptide. Boxed areas are shown at higher magnification to the right. Scale bars: $200 \mu \mathrm{m}$ (left); $50 \mu \mathrm{m}$ (right). Original magnification: $\times 100$ (left); $\times 400$ (right).

antibody A, had an exclusive localization in the nuclear-free fraction; the antibody B that also recognizes Pro-Lox evidenced the same pattern (not shown). The 32-kDa Lox active enzyme, recognized by antibody A, had a nuclear localization and a weak localization in the nuclear-free fraction. Both proteins, Pro-Lox and Lox, were prevalent in ccRCC cells with respect to normal cells but not in a significant way. With antibody $\mathrm{B}$, the $18-\mathrm{kDa}$ Lox-PP propeptide had an exclusive nuclear localization with a significantly stronger signal in normal cortex cells with respect to ccRCC cells.

Even immunofluorescence analysis (Figure 2C) supported these data. With antibody $\mathrm{A}$, the nuclear signal was evident in normal and tumor cells and based on
Western blot data had to be ascribed to 32-kDa Lox, whereas the cytoplasmic signal represented both $50-\mathrm{kDa}$ Pro-Lox and 32-kDa Lox. With antibody B, the nuclear fluorescent signal was well evidenced, mainly in cortex cells, and had to be ascribed to $18-\mathrm{kDa}$ Lox-PP. The cytoplasmic signal in ccRCC cells had a characteristic localization that leaned toward cellular membrane, and based on Western data, it should be exclusively due to 50-kDa Pro-Lox.

Then we evaluated the presence of $32-\mathrm{kDa}$ active Lox enzyme in five media of cortex and HIF- $1 \alpha$-expressing ccRCC cultures (Figure 2D). Lox enzyme was significantly more abundant in the ccRCC primary cell culture media than in those of cortex.

Table 2 LOX Immunoreactivity Evaluated by Antibodies A and B in Clear Cell Renal Cell Carcinoma Tissues

\begin{tabular}{|c|c|c|c|c|c|c|c|c|c|c|c|}
\hline \multicolumn{6}{|l|}{ Antibody A } & \multicolumn{6}{|l|}{ Antibody B } \\
\hline \multicolumn{3}{|c|}{ Nuclear staining $(\%)^{*}$} & \multicolumn{3}{|c|}{ Cytoplasm staining $(\%)^{*}$} & \multicolumn{3}{|c|}{ Nuclear staining $(\%)^{*}$} & \multicolumn{3}{|c|}{ Cytoplasm staining $(\%)^{*}$} \\
\hline & Positive & & & Positive & & & Positive & & & Positive & \\
\hline $91.97 \pm 1.86$ & $8.03 \pm 1.86$ & 0 & 0 & $82.57 \pm 3.35$ & $17.43 \pm 3.35$ & $11.67 \pm 2.77$ & $71.48 \pm 4.68$ & $16.85 \pm 6.24$ & $10.62 \pm 1.47$ & $89.38 \pm 1.47$ & 0 \\
\hline
\end{tabular}

${ }^{*}$ Means \pm SEM of the percentage of cells evaluated in five different fields of each for eight different tumor specimens.

$M$, only an intensified signal against the membrane borders; $C+M$, weak cytoplasmic signal and an intensified signal against the membrane borders. 

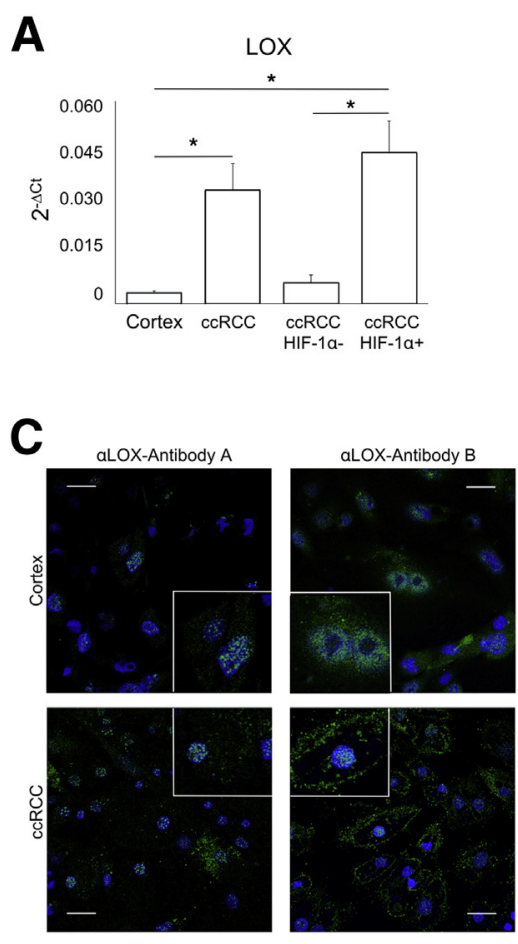

D

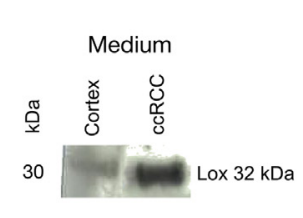

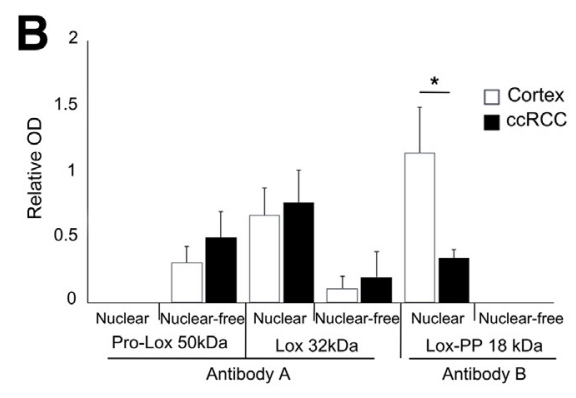
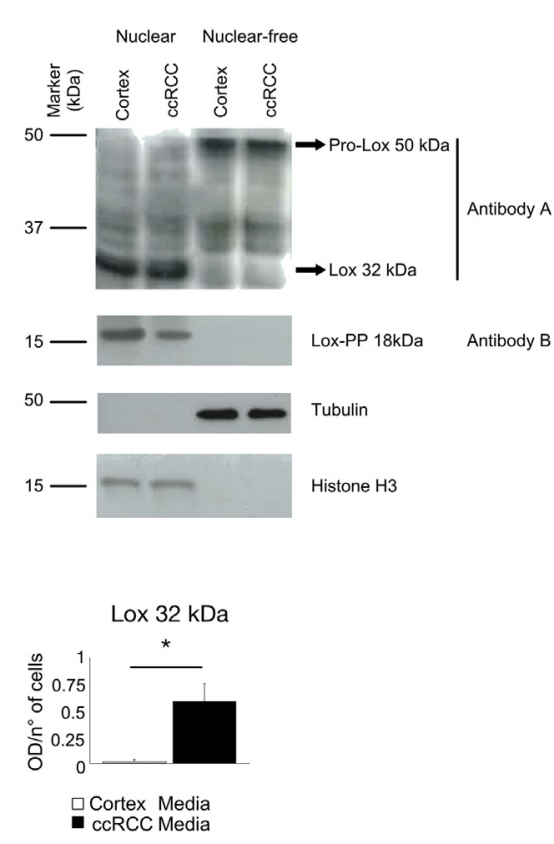

Figure 2 Lox expression in primary cell cultures of normal cortex and clear cell renal cell carcinoma (ccRCC). A: Real-time PCR of LOX transcript in 24 matched normal cortex and ccRCC primary cell cultures; 18 cultures expressed hypoxia-inducible factor (HIF)- $1 \alpha$ protein, and six cultures did not. B: Quantification of subcellular localization (nuclear and nuclear-free fractions) of Pro-Lox proenzyme $(50 \mathrm{kDa})$, active Lox enzyme (32 $\mathrm{kDa})$, and Lox-PP propeptide (18 kDa) in primary cell cultures of five different cases. The optical density (OD) values were normalized by the values of tubulin or histone $\mathrm{H} 3$ bands. The antibodies used are indicated and representative Western blot with specific bands and molecular weight markers are reported. C: Immunofluorescence with the indicated antibody against LOX ( $\alpha$ LOX) in cortex and ccRCC primary cell cultures. In the insets, the presence of LOX signal in the nucleus is shown. D: Quantification of $32-k D a$ Lox peptide detected with antibody $A$ in conditioned media of primary cell cultures of five different cases; representative Western blot is reported. The $O D$ values were normalized by the number of cells collected from each plate. All ccRCC primary cell cultures in B, C, and D expressed HIF- $1 \alpha$. ${ }^{*} P<0.05$ ( $t$-test). Scale bars $=10 \mu \mathrm{m}$. Original magnification, $\times 2$ (C, insets).

\section{HIF-1 $\alpha$ Expression and Cell Proliferation Decreases after Silencing of Endogenous LOX in ccRCC Primary Cell Cultures Expressing HIF-1 $\alpha$}

LOX and HIF- $1 \alpha$, in colon cancer cell lines, have been reported to potentiate each other to sustain tumor progression. $^{23}$ To verify this regulative loop in ccRCC, we silenced endogenous $L O X$ gene expression by siRNA transfection in HIF- $1 \alpha$-expressing ccRCC primary cell cultures, obtaining $>90 \%$ of Pro-Lox protein knockdown 48 hours after silencing (Figure 3A and Supplemental Figure S1A). This strong down-regulation has also been observed for LOX mRNA and for intracellular active Lox enzyme and Lox-PP (not shown). We observed a down-regulation of HIF-1 $\alpha$ protein in LOX-silenced ccRCC cells (Figure 3A), as also documented by the mRNA reduction of three targets of the HIF- $1 \alpha$ transcriptional activity, TGF- $\beta 3$, Snail, and Zeb2 (Figure 3B). The ccRCC primary cell cultures obtained from eight different cases did not reveal significant differences in the proliferating activity, evaluated with MTT assay after 48 hours of LOX silencing, with respect to controls. On the other hand, when the samples were stratified based on HIF$1 \alpha$ expression, only in the five cases expressing HIF- $1 \alpha$ did the silenced cultures have a significant cell proliferation decrement (Figure 3C), without an apoptosis rate change (Figure 3D). After silencing, the strong down-regulation of cellular Lox-PP did not evidence the effects of lack of LoxPP oncosuppressor actions on cellular proliferation and apoptosis.

Endogenous LOX Regulates ccRCC Primary Cell Cultures Migration, Cell-Matrix Adhesion, Cell-Cell Contact, and Invasion

Because overexpression of LOX has been associated with the promotion of cellular adhesion and migration, favoring tumor progression, invasion, and metastasis of different tumors, ${ }^{13,14,18}$ we investigated the functional role of endogenous LOX in ccRCC cells expressing HIF-1 $\alpha$. LOX silencing in ccRCC primary cell cultures not only blocked the production of Pro-Lox (Figure 3A and Supplemental Figure S1A) but, as a consequence, the $32-\mathrm{kDa}$ Lox was strongly down-regulated in the corresponding conditioned media (Figure 4A). In LOX silenced ccRCC cultures, ECMindependent cell migration has been studied by Boyden chamber and wound healing assay. Both migration assays revealed that ccRCC primary cultures, after siRNA LOX treatment, migrated less than control samples (Figure 4, B 
A
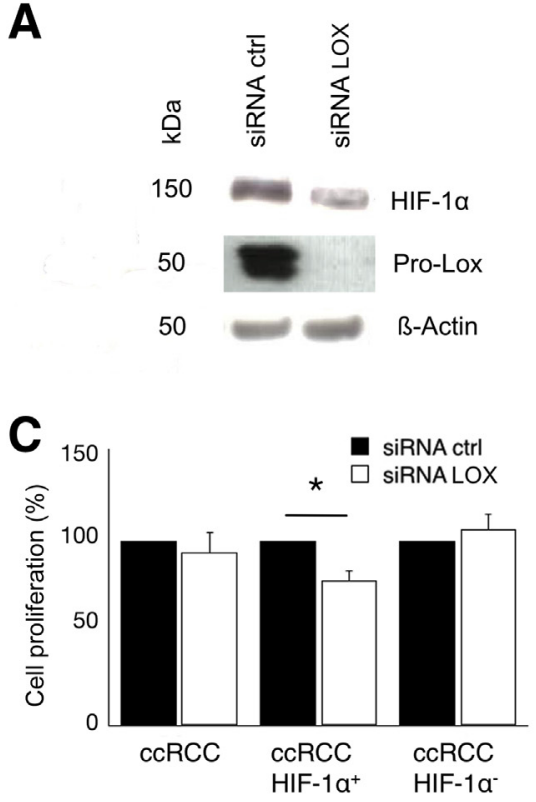

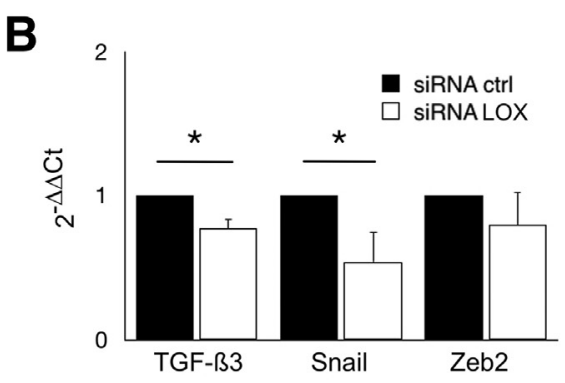

D

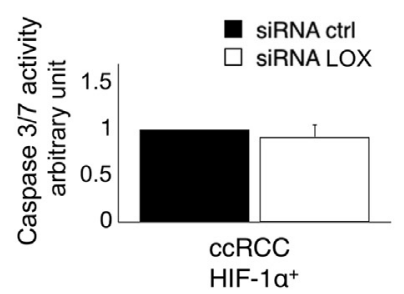

Figure 3 Effects of siRNA LOX and siRNA control (ctrl) treatment in hypoxia-inducible factor (HIF)- $1 \alpha$-expressing clear cell renal cell carcinoma (ccRCC) primary cell cultures. A: Representative Western blot of cellular protein lysate reveals the bands of indicated protein after treatment. Pro-Lox has been tested with antibody A. B: Transforming growth factor (TGF)- $\beta 3$, Snail, and Zeb2 transcripts evaluated by real-time PCR. The relative amount of the transcripts, calculated as $2^{-\Delta \Delta \mathrm{ct}}$, revealed the fold-change with respect to the corresponding control samples considered equal to 1. C: Percentage of cell proliferation evaluated with MTT assay in eight cCRCC primary cell cultures (five expressed HIF-1 $\alpha$ and three did not) with respect to corresponding controls. D: Apoptosis rate evaluation through caspase $3 / 7$ assay. Caspase activity expressed as fold-change with respect to control. ${ }^{*} P<0.05$ ( $t$-test). and $\mathrm{C}$ ), supporting a LOX role in the cellular migratory machinery of ccRCC cells.

We also analyzed the cell adhesion after LOX knockdown that in ccRCC led to a decrease in cell adhesion on both plastic and fibronectin-coated plates (Figure 4D) and to a different reorganization of focal adhesions (FAs) evidenced by immunofluorescence, staining the specific marker paxillin (Supplemental Figure S1B). In silenced tumor cells FAs had a predominant peripheral distribution, whereas in the control cells they were distributed throughout the cytoplasm. In addition, the phosphorylated (Y118) paxillin, a marker of FA stability, ${ }^{38}$ decreased in ccRCC cells (Supplemental Figure S1B).

The cell adhesion molecule N-cadherin mediates the cellcell contact and is characteristically expressed by the epithelial proximal tubule cells ${ }^{39,40}$ (Supplemental Figure S1C) from which ccRCC originates $^{30,41}$ and therefore has a negligible expression of E-cadherin (Supplemental Figure S1, C and D). N-Cadherin was up-regulated in ccRCC primary cell cultures after LOX silencing; instead, vimentin, $\alpha$-smooth muscle actin and cytokeratin expression did not significantly change (Figure 4E and Supplemental Figure S1, $\mathrm{E}$ and $\mathrm{F}$ ). Taken together, these results suggested that endogenous LOX overexpression in ccRCC primary cultures may promote cell-matrix adhesion ability and decrease cellcell contact.

To assess the role of LOX in the invasion process in our cellular model, we performed an invasion assay using a collagen-coated membrane. siRNA LOX reduced the invasion capability of cancer cells with respect to control cells (Figure 4F). These data supported a mechanistic link between the endogenous production of Pro-Lox, with the presence of secreted and intracellular LOX peptides, and the migratory phenotype with invasion capacities of ccRCC primary cells.
Endogenous LOX Secreted by ccRCC Cells Modifies the Collagen Matrix Stiffness

Tumor progression has been correlated with LOX capacity to crosslink collagen and increase ECM stiffness. ${ }^{15,16}$ The wide decrement of invading cells, after LOX silencing, led us to test the role of ccRCC extracellular Lox enzyme in regulating collagen matrix stiffness. We quantified the mechanical effects of secreted LOX on collagen-coated gels using the atomic force microscopy technique and calculating the values of the Young modulus. The ccRCC conditioned media, in which Lox is present, induced a significant increase of collagen matrix stiffness evidenced by the Young modulus that is higher by a factor of $1.30 \pm 0.32$ (means \pm SEM) with respect to the value of collagen matrixes treated with fresh control media (Figure 4G). The presence of $\beta A P N$ LOX inhibitor in ccRCC-conditioned media prevented collagen matrix from becoming stiffer, resulting in a insignificant variation of Young modulus $(0.90 \pm 0.23)$ with respect to the control media treatment. These data were confirmed even by using the conditioned medium of LOX silenced ccRCC cells (Supplemental Figure S1G). Overall, the stiffness measurements highlighted that the active Lox constitutively produced by ccRCC increased the collagen matrix stiffness.

\section{Discussion}

The ccRCC is the most frequent malignant neoplasm of the kidney, and, despite the recent introduction of tyrosine kinase, mechanistic target of rapamycin, and vascular endothelial growth factor inhibitors in clinical practice, it still remains a therapy-resistant tumor. ${ }^{2}$ Therefore, it is important to understand better the molecular mechanisms of 

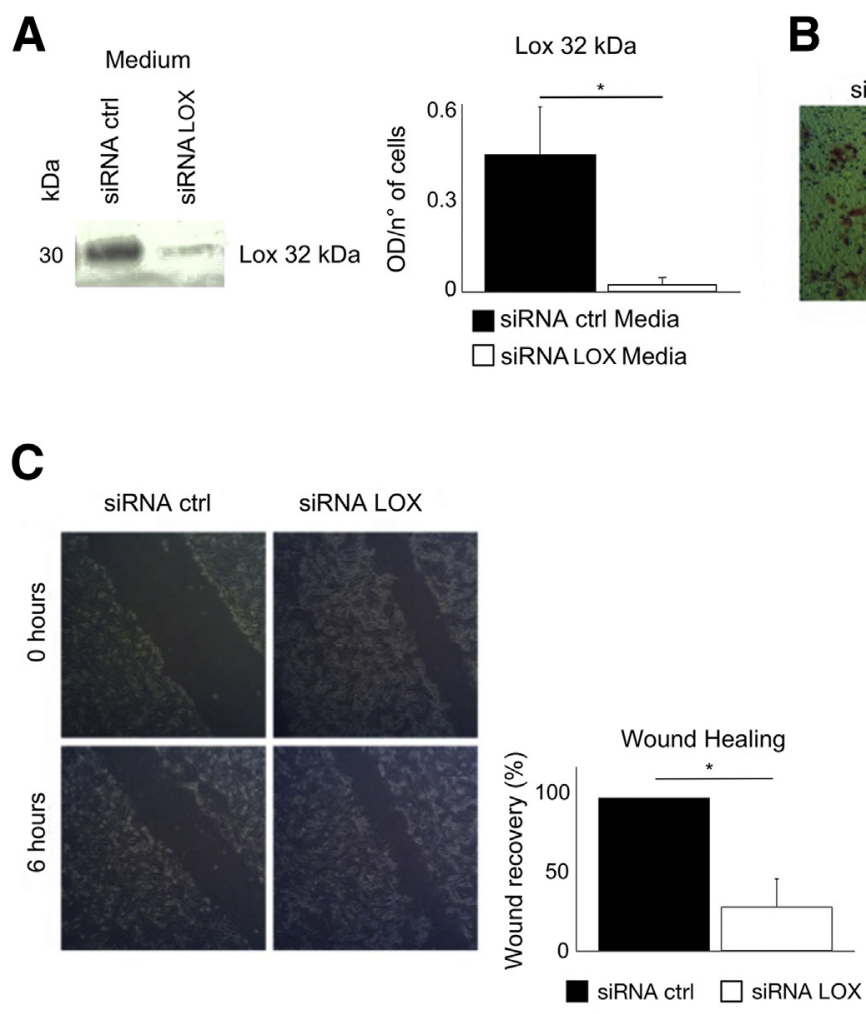

$\mathbf{F}$

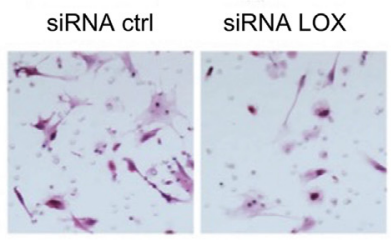

B

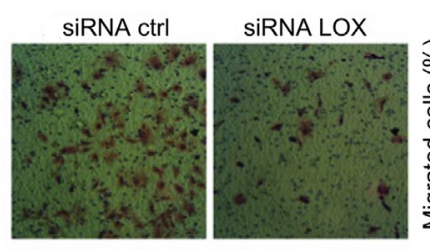

D

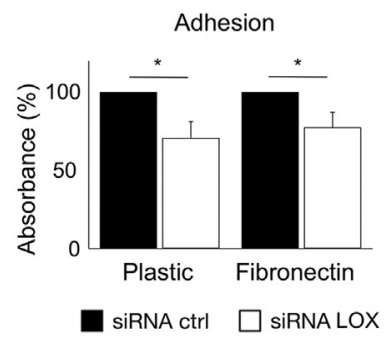

E
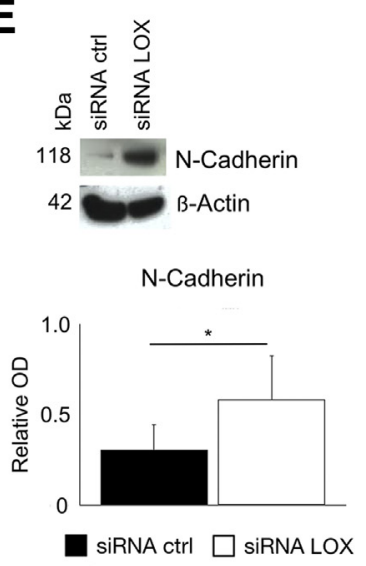

G

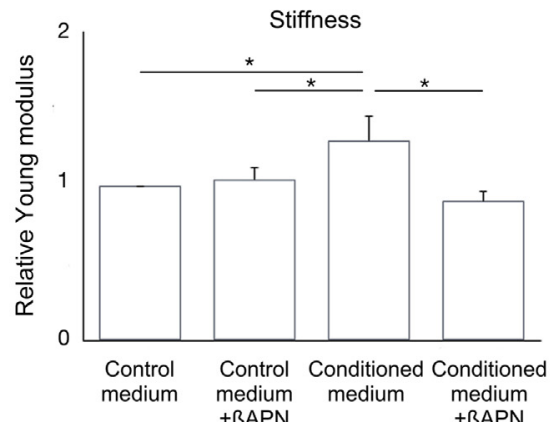

Figure 4 Effects of LOX silencing on cellular migration, adhesion, invasion, and collagen stiffness regulation in clear cell renal cell carinoma (ccRCC) primary cell cultures expressing hypoxia-inducible factor (HIF)-1 $1 \alpha$. A: Representative Western blot of active Lox, tested with antibody A in conditioned culture media of LOX silenced and control cells. The graph indicates the band optical density (OD) normalized by the number of cells collected from each plate. B: Representative hematoxylin and eosin (H\&E) staining of migrated cells in Boyden chamber. The graph represents the percentage of cells migrated after 8 hours. C: Representative phase contrast images after the scratch ( 0 hours) and after 6 hours of wound recovery. The graph represents the percentage of wound recovery. D: Adhesion assay has been performed on 12-well plates coated or not with fibronectin. The graph shows the percentage of absorbance measured at $590 \mathrm{~nm}$. E: Representative Western blot assay and relative densitometric analysis of N-cadherin normalized by $\beta$-actin in siRNA control and siRNA LOX primary cultures. F: Cell invasion assay performed in Boyden chamber coated by collagen; representative images for migrated cells stained with H\&E. The graph represents the percentage of invading cells. G: Evaluation of collagen matrix stiffness after treatment with control medium, control medium containing LOX inhibitor $\beta A P N$, conditioned medium of ccRCC primary cultures expressing HIF- $1 \alpha$, and the same ccRCC conditioned medium containing $\beta A P N$. Data were represented as fold-change with respect to control medium considered equal to $1 .{ }^{*} P<0.05$ ( $t$-test). Original magnification, $\times 100$ (B, $\mathbf{C}$, and $\mathbf{F}$ ).

onset and progression of ccRCC to identify candidate targets for novel molecular therapies. The functional analysis of 1049 differentially modulated genes obtained from comparing ccRCC primary cell cultures with normal cortex primary cell cultures revealed significant enrichments of several biological processes of GO category known to be important for ccRCC invasion and progression. ${ }^{8}$ Moreover, by comparing the transcriptomic profile of the present study to the list of 2493 DEGs obtained in ccRCC tissues, ${ }^{8}$ we found that several important GO biological process categories involved in tumor progression were shared by the two data sets. Thus, transcriptomic analysis of primary cell cultures and meta-analysis indicated that our in vitro model well mimicked the molecular signature of ccRCC tissues. Because tumor progression depends on the context of the surrounding tissue ${ }^{42}$ and ccRCC is highly vascularized, this 
suggests that remodeling of the tumor microenvironment may play an important role in ccRCC progression. LOX, which is represented in the enriched GO biological processes related to ccRCC progression, is one of the major candidates for this remodeling. ${ }^{10}$ Of note, overexpression of LOX is reported in our data, as well as in seven ccRCC tissue data sets available in Oncomine Research Edition database (Oncomine, www.oncomine.org, last accessed October 13, 2015) (Supplemental Table S5) and in the previous literature. ${ }^{25-28}$ This widely confirmed overexpression of LOX in ccRCC may subtend to the accomplishment of actions related to tumor progression ${ }^{10}$; however, LOX has never been investigated in detail in human ccRCC. To gain insight to the role of endogenous LOX in ccRCC, we used our primary cell cultures of renal cortex and ccRCC. The similarity of these cultures with the original tissue ${ }^{29-31}$ made them particularly suitable for functional studies; in addition, their cytological homogeneity permitted a direct comparison between normal and tumor cells. With normal human kidney tissue, such a direct comparison was difficult because the expression of LOX was highly heterogeneous and cell type related. On the basis of our data, it was possible to argue that both Pro-Lox and Lox are localized in cytoplasm, with the prevalence of ProLox that was more abundant in ccRCC also shown by transcriptomic and PCR data. Antibody B in nuclear-free fraction recognized only Pro-Lox, and the immunofluorescence signal in ccRCC cells had a characteristic localization leaning toward plasma membrane, probably related to ProLox extracellular secretion that could be enhanced in ccRCC cells. Instead, antibody A that recognized Pro-Lox and Lox hampered the observation of this characteristic cytoplasm localization of Pro-Lox in primary cell cultures. Most of the 32-kDa Lox was nuclear in our normal and ccRCC epithelial cells, as also documented by immunofluorescence, and this localization was coherent with the interaction of Lox with $\mathrm{H} 1$ to $\mathrm{H} 2$ histone proteins described in fibroblasts. ${ }^{19}$ Lox-PP was exclusively nuclear, and its abundance in cortex cells was coherent with its oncosuppressor role. ${ }^{22,43,44}$

The mutual link between LOX and HIF- $1 \alpha$, documented by HIF- $1 \alpha$ protein decrement in LOX silenced ccRCC cells, suggested that signaling pathway integration of HIF and LOX in diverse cell types is not an unusual event. In fact, in normoxic and hypoxic colon cancer cell lines, it has been described that recombinant LOX and HIF- $1 \alpha$ modulate each other. This process is elicited by reactive oxygen species, through activation of phosphatidylinositol 3-kinase/mechanistic target of rapamycin pathway and the downstream kinases PDK1 and AKT. ${ }^{23}$ The down-regulation of HIF- $1 \alpha$ protein by LOX silencing may also explain the proliferation reduction that we observed in our LOX silenced ccRCC primary cultures expressing HIF-1 $\alpha$. In effect, it has been reported that, in colon cancer cell lines, LOX is able to stimulate cell proliferation in an HIF- $1 \alpha$-dependent manner through phosphatidylinositol 3-kinase ${ }^{23}$ and $\mathrm{Src}^{18}$ activation. Coherently with this interpretation, in our LOX silenced HIF- $1 \alpha-$ negative ccRCC primary cell cultures, the cell proliferation was not significantly affected.

In our primary cultures, the role of endogenous LOX was confirmed in providing a strong migratory and invasive cellular phenotype to ccRCC cells. In this model, the LOX knockdown caused a decrease in ccRCC cellular adhesion on plastic and fibronectin-coated surfaces with a reorganization of FAs to the cell periphery, in contrast with their localization throughout the cytoplasm in control cells. The reorganization of FAs with the finding of paxillin-PY118 reduction, even in ccRCC, agrees with the role of LOX in modulation of FA dynamics. ${ }^{13-15,38,45}$

The impairment of cell-cell adhesion molecules can be an important aspect of tumor progression, ${ }^{41}$ and the cell-cell adhesion marker $\mathrm{N}$-cadherin is characteristic of epithelial proximal tubule cells that do not express E-cadherin. ${ }^{39-41}$ ccRCC deriving from proximal tubule cells ${ }^{30,33}$ did not express E-cadherin but only N-cadherin (Supplemental Figure S1, C and D). It is suggestive that in ccRCC, in which there is a constitutive up-regulation of LOX, the knockdown of the LOX protein was associated with not only a decrement of cellular adhesion on plastic and fibronectin but also an increment of $\mathrm{N}$-cadherin. This finding could suggest that the constitutive up-regulation of endogenous LOX in ccRCC is responsible for a negative modulation of $\mathrm{N}$-cadherin and a reduced cell-cell adhesion of ccRCC.

All these data indicated that in ccRCC cells LOX determines and maintains an invasive phenotype. In fact, the absence of endogenous LOX heavily impaired the invasion capacity of ccRCC cells on collagen. The lack of LOX-mediated crosslinking action prevented matrix stiffness increment, where a stiffer environment is associated with activation of FAK/Src signaling and a more invasive phenotype. ${ }^{15}$ We highlighted this aspect by revealing the ability of conditioned media of ccRCC cells, which secreted and produced active Lox, to increase collagen matrix stiffness. The cumulative effects of LOX ECM remodeling and the consequent tissue stiffness increment ${ }^{15}$ could have a role in the frequency by which ccRCC grows in vena cava as a stable thrombus. ${ }^{46}$

In conclusion, there is increasing evidence of the importance of LOX in clinical oncology. ${ }^{24,44,47,48}$ In ccRCC, as indicated by our data, it seems that endogenous LOX overexpression, favored by constitutive expression of HIF- $1 \alpha$, plays a major action in tumor progression, and through the secreted LOX, the ECM stiffness is modulated. Despite LOX overexpression, the oncosuppressive action of Lox-PP is not prevailing. These findings could indicate new therapeutic strategies by targeting selectively the two peptides.

\section{Acknowledgments}

We thank Massimiliano Cadamuro (Milano-Bicocca University) for support with the IHC assay, Nicola Zucchini 
for revision of the IHC slides, and Karen Boullier for proofreading.

\section{Supplemental Data}

Supplemental material for this article can be found at http://dx.doi.org/10.1016/j.ajpath.2016.05.019.

\section{References}

1. Rini BI, Campbell SC, Escudier B, Roussy IG: Renal cell carcinoma. Lancet 2009, 373:1119-1132

2. Alonso AH, García MC, Enguita CG: Is there a role for systemic targeted therapy after surgical treatment for metastases of renal cell carcinoma? World J Nephrol 2015, 4:254-262

3. Young AC, Craven RA, Cohen D, Taylor C, Booth C, Harnden P, Cairns DA, Astuti D, Gregory W, Maher ER, Knowles MA, Joyce A, Selby PJ, Banks RE: Analysis of VHL gene alterations and their relationship to clinical parameters in sporadic conventional renal cell carcinoma. Clin Cancer Res 2010, 15:7582-7592

4. Cancer Genome Atlas Research Network: Comprehensive molecular characterization of clear cell renal cell carcinoma. Nature 2013, 499: 43-49

5. Shen C, Beroukhim R, Schumacher SE, Zhou J, Chang M, Signoretti S, Kaelin WG: Genetic and functional studies implicate HIF1 as a $14 \mathrm{q}$ kidney cancer suppressor gene. Cancer Discov 2011, 1:222-235

6. Semenza GL: Targeting HIF-1 for cancer therapy. Nat Rev Cancer 2003, 3:721-732

7. Keith B, Johnson RS, Simon MC: HIF1 $\alpha$ and HIF2 $\alpha$ : sibling rivalry in hypoxic tumour growth and progression. Nat Rev Cancer 2011, 12 : 9-22

8. Wozniak MB, Le Calvez-kelm F, Abedi-ardekani B, Byrnes G, Durand G, Carreira C, Michelon J, Janout V, Holcatova I, Foretova L, Brisuda A, Lesueur F, McKay J, Brennan P, Scelo G: Integrative genome-wide gene expression profiling of clear cell renal cell carcinoma in Czech Republic and in the United States. PLoS One 2013, 8:e57886

9. Wettersten HI, Hakimi AA, Morin D, Bianchi C, Johnstone ME, Donohoe DR, Trott JF, Aboud OA, Stirdivant S, Neri B, Wolfert R, Stewart B, Perego R, Hsieh JJ, Weiss RH: Grade-dependent metabolic reprogramming in kidney cancer revealed by combined proteomics and metabolomics analysis. Cancer Res 2015, 75:2541-2552

10. Barker HE, Cox TR, Erler JT: The rationale for targeting the LOX family in cancer. Nat Rev Cancer 2012, 12:540-552

11. Trackman PC, Bedell-Hogan D, Tang J, Kagan HM: Post-translational glycosylation and proteolytic processing of a lysyl oxidase precursor. J Biol Chem 1992, 267:8666-8671

12. Perryman L, Erler JT: Lysyl oxidase in cancer research. Future Oncol 2014, 10:1709-1717

13. Payne SL, Fogelgren B, Hess AR, Seftor EA, Wiley EL, Fong SF, Csiszar K, Hendrix MJ, Kirschmann DA: Lysyl oxidase regulates breast cancer cell migration and adhesion through a hydrogen peroxide mediated mechanism. Cancer Res 2005, 65:11429-11436

14. Laczko R, Szauter KM, Jansen MK, Hollosi P, Muranyi M, Molnar J, Fong KS, Hinek A, Csiszar K: Active lysyl oxidase (LOX) correlates with focal adhesion kinase (FAK)/paxillin activation and migration in invasive astrocytes. Neuropathol Appl Neurobiol 2007, 33:631-643

15. Baker A, Bird D, Lang G, Cox TR, Erler JT: Lysyl oxidase enzymatic function increases stiffness to drive colorectal cancer progression through FAK. Oncogene 2013, 32:1863-1868

16. Cox TR, Rumney RM, Schoof EM, Perryman L, Hoye AM, Agrawal A, Bird D, Latif NA, Forrest H, Evans HR, Huggins ID, Lang G, Linding R, Gartland A, Erler JT: The hypoxic cancer secretome induces pre-metastatic bone lesions through Lysyl Oxidase. Nature 2015, 522:106-110

17. Payne SL, Hendrix MJ, Kirschmann DA: Paradoxical roles for lysyl oxidases in cancer - a prospect. J Cell Biochem 2007, 101: $1338-1354$

18. Baker A, Cox TR, Bird D, Lang G, Murray GI, Sun X, Southall SM, Wilson JR, Erler JT: The role of lysyl oxidase in SRC-dependent proliferation and metastasis of colorectal cancer. J Natl Cancer Inst 2011, 103:407-424

19. Li W, Nellaiappan K, Strassmaier T, Graham L, Thomas KM, Kagan HM: Localization and activity of lysyl oxidase within nuclei of fibrogenic cells. Proc Natl Acad Sci U S A 1997, 94:12817-12822

20. Palamakumbura AH, Jeay S, Guo Y, Pischon N, Sommer P, Sonenshein GE, Trackman PC: The propeptide domain of lysyl oxidase induces phenotypic reversion of ras-transformed cells. J Biol Chem 2004, 279:40593-40600

21. Bais MV, Nugent MA, Stephens DN, Sume SS, Kirsch KH, Gail E, Trackman PC: Recombinant lysyl oxidase propeptide protein inhibits growth and promotes apoptosis of pre-existing murine breast cancer xenografts. PLoS One 2012, 7:e31188

22. Bais MV, Ozdener GB, Sonenshein GE, Trackman PC: Effects of tumor-suppressor lysyl oxidase propeptide on prostate cancer xenograft growth and its direct interactions with DNA repair pathways. Oncogene 2015, 34:1928-1937

23. Pez F, Dayan F, Durivault J, Kaniewski B, Aimond G, Le Provost GS, Deux B, Clézardine P, Sommer P, Pouysségur J, Reynaud C: The HIF1 inducible lysyl oxidase activates HIF-1 via the Akt pathway in a positive regulation loop and synergizes with HIF-1 in promoting tumor cell growth. Cancer Res 2011, 71:1647-1657

24. Friesenhengst A, Pribitzer-Winner T, Schreiber M: Association of the G473A polymorphism and expression of lysyl oxidase with breast cancer risk and survival in European women: a hospital-based casecontrol study. PLoS One 2014, 9:e105579

25. Young AN, Amin MB, Moreno CS, Lim SD, Cohen C, Petros JA, Marshal FF, Neish AS: Expression profiling of renal epithelial neoplasms a method for tumor classification and discovery of diagnostic molecular markers. Am J Pathol 2001, 158:1639-1651

26. Takahashi M, Rhodes DR, Furge KA, Kanayama H, Kagawa S, Haab BB, Teh BT: Gene expression profiling of clear cell renal cell carcinoma: gene identification and prognostic classification. Proc Natl Acad Sci U S A 2001, 98:9754-9759

27. Cifola I, Spinelli R, Beltrame L, Peano C, Fasoli E, Ferrero S, Bosari S, Signorini S, Rocco F, Perego R, Proserpio V, Raimondo F, Mocarelli P, Battaglia C: Genome-wide screening of copy number alterations and $\mathrm{LOH}$ events in renal cell carcinomas and integration with gene expression profile. Mol Cancer 2008, 7:6

28. Ross DT, Scherf U, Eisen MB, Perou CM, Rees C, Spellman P, Iyer V, Jeffrey SS, Van De Rijn M, Waltham M, Pergamenschikov A, Lee JC, Lashkari D, Shalon D, Myers TG, Weinstein JN, Botstein D, Brown PO: Systematic variation in gene expression patterns in human cancer cell lines. Nat Genet 2000, 24:227-235

29. Perego RA, Bianchi C, Corizzato M, Eroini B, Torsello B, Valsecchi C, Di Fonzo A, Cordani N, Favini P, Ferrero S, Pitto M, Sarto C, Magni F, Rocco F, Mocarelli P: Primary cell cultures arising from normal kidney and renal cell carcinoma retain the proteomic profile of corresponding tissues. J Proteome Res 2005, 4:1503-1510

30. Bianchi C, Bombelli S, Raimondo F, Torsello B, Angeloni V, Ferrero S, Di Stefano V, Chinello C, Cifola I, Invernizzi L, Brambilla P, Magni F, Pitto M, Zanetti G, Mocarelli P, Perego RA: Primary cell cultures from human renal cortex and renal-cell carcinoma evidence a differential expression of two spliced isoforms of Annexin A3. Am J Pathol 2010, 176:1660-1670

31. Cifola I, Bianchi C, Mangano E, Bombelli S, Frascati F, Fasoli E, Ferrero S, Di Stefano V, Zipeto MA, Magni F, Signorini S, Battaglia C, Perego RA: Renal cell carcinoma primary cultures maintain genomic and phenotypic profile of parental tumor tissues. BMC Cancer 2011, 11:244 
32. Grignon DJ, Eble JN, Bonsib SM, Moch H: Clear cell renal cell carcinoma. Edited by Eble JN, Sauter G, Epstein JI, Sesterhenn IA. In: WHO Classification of Tumours. Pathology and Genetics of Tumours of the Urinary System and Male Genital Organs. Lyon, France: IARC Press, 2004, pp 23-25

33. Shen SS, Krishna B, Chirala R, Amato RJ, Truong LD: Kidneyspecific cadherin, a specific marker for the distal portion of the nephron and related renal neoplasms. Mod Pathol 2005, 18: 933-940

34. Kaimal V, Bardes EE, Tabar SC, Jegga AG, Aronow BJ: ToppCluster: a multiple gene list feature analyzer for comparative enrichment clustering and network-based dissection of biological systems. Nucleic Acids Res 2010, 38:W96-W102

35. Bianchi C, Torsello B, Di Stefano V, Zipeto M, Facchetti R, Bombelli S, Perego RA: One isoform of Arg/Abl2 tyrosine kinase is nuclear and the other seven cytosolic isoforms differently modulate cell morphology, motility and the cytoskeleton. Exp Cell Res 2013, 319:2091-2102

36. Chaudhuri T, Rehfeldt F, Sweeney HL, Discher DE: Preparation of collagen-coated gels that maximize in vitro myogenesis of stem cells by matching the lateral elasticity of in vivo muscle. Methods Mol Biol 2010, 621:185-202

37. Higgins DF, Kimura K, Bernhardt WM, Shrimanker N, Akai Y, Hohenstein B, Saito Y, Johnson RS, Kretzler M, Cohen CD, Eckardt K, Iwano M, Haase VH: Hypoxia promotes fibrogenesis in vivo via HIF-1 stimulation of epithelial-to-mesenchymal transition. J Clin Invest 2007, 117:3810-3820

38. Colò GP, Hernandez-varas P, Lock J, Bartolomè RA, ArellanoSanchez N, Stromblad S, Teixido J: Focal adhesion disassembly is regulated by a RIAM to MEK-1 pathway. J Cell Sci 2012, 125: $5338-5352$

39. Keller C, Kroening S, Zuehlke J, Kunath F, Krueger B, GoppeltStruebe M: Distinct mesenchymal alterations in N-Cadherin and
E-Cadherin positive primary renal epithelial cells. PLoS One 2012, 7: e43584

40. Bombelli S, Zipeto MA, Torsello B, Bovo G, Di Stefano V, Bugarin C, Zordan P, Viganò P, Cattoretti G, Strada G, Bianchi C, Perego RA: $\mathrm{PKH}$ (high) cells within clonal human nephrospheres provide a purified adult renal stem cell population. Stem Cell Res 2013, 11:1163-1177

41. Shimazui T, Kojima T, Onozawa M, Suzuki M, Asano T, Akaza H: Expression profile of $\mathrm{N}$-cadherin differs from other classical cadherins as a prognostic marker in renal cell carcinoma. Oncol Rep 2006, 15: $1181-1184$

42. Pickup MW, Mouw JK, Weaver VM: The extracellular matrix modulates the hallmarks of cancer. EMBO Rep 2014, 15:1243-1253

43. Palamakumbura AH, Vora SR, Nugent MA, Kirsch KH, Sonenshein GE, Trackman PC: Lysyl oxidase propeptide inhibits prostate cancer cell growth by mechanisms that target FGF-2-cell binding and signaling. Oncogene 2009, 28:3390-3400

44. Zheng Y, Wang X, Wang H, Yan W, Zhang Q, Chang X: Expression of the lysyl oxidase propeptide in hepatocellular carcinoma and its clinical relevance. Oncol Rep 2014, 31:1669-1676

45. Chen LC, Tu SH, Huang CS, Chen CS, Ho CT, Lin HW, Lee CH, Chang HW, Chang CH, Wu CH, Lee WS, Ho YS: Human breast cancer cell metastasis is attenuated by lysyl oxidase inhibitors through down-regulation of focal adhesion kinase and the paxillin-signaling pathway. Breast Cancer Res 2012, 134:989-1004

46. Boorjian SA, Sengupta S, Blute ML: Renal cell carcinoma: vena caval involvement. BJU Int 2007, 99:1239-1244

47. Cheng G, Li J, Zheng M, Zhao Y, Zhou J, Li W: NNK, a tobaccospecific carcinogen, inhibits the expression of lysyl oxidase, a tumor suppressor. Int J Env Res Publ Health 2015, 12:64-82

48. Sung FL, Cui Y, Hui EP, Li L, Loh TK, Tao Q, Chan ATC: Silencing of hypoxia-inducible tumor suppressor lysyl oxidase gene by promoter methylation activates carbonic anhydrase IX in nasopharyngeal carcinoma. Am J Cancer Res 2014, 4:789-800 